CHRONIC OBSTRUCTIVE PULMONARY DISEASE

\title{
Bronchoscopic validation of the significance of sputum purulence in severe exacerbations of chronic obstructive pulmonary disease
}

\author{
Néstor Soler, Carlos Agustí, Joaquim Angrill, Jorge Puig De la Bellacasa, Antoni Torres
}

Thorax 2007;62:29-35. doi: 10.1136/thx.2005.056374

See end of article for authors' affiliations

Correspondence to Dr A Torres, Servei de Pneumologia, Institut Clínic del Tòrax, Hospital Clínic, IDIBAPS Universitat de Barcelona, Villarroel 170 08036 Barcelona, Spain; atorres@ub.edu

Received 25 November 2005 Accepted 16 July 2006 Published Online First 23 August 2006
Background: Antibiotics are commonly prescribed in exacerbations of chronic obstructive pulmonary disease (COPD). However, the role of bacteria in these exacerbations is controversial.

Objective: To identify clinical predictors of bacterial infection as a cause of exacerbation, considering the protected specimen brush (PSB) as the gold standard.

Methods: Clinical data, sputum and PSB samples were collected from 40 patients with COPD requiring hospitalisation due to severe exacerbations who had not received previous antibiotic treatment.

Results: Quantitative cultures of PSB samples $(n=40)$ yielded 23 potential pathogenic microorganisms (PPMs) at concentrations of $\geqslant 10^{2}$ colony-forming units $/ \mathrm{ml}$ in $18(45 \%)$ patients. Sputum samples were obtained from all 40 patients. Culture of good-quality sputum samples $(n=18)$ yielded 16 PPMs corresponding to $14(35 \%)$ patients. The concordance between the PSB and sputum rate was high $(\kappa=0.85, \mathrm{p}<0.002)$. The selfreporting patient observation of sputum purulence (odds ratio (OR) 27.20 (95\% confidence interval (Cl) 4.60 to 60.69$), p=0.001$ ), the percentage predicted forced expiratory volume in $1 \mathrm{~s}(\mathrm{FEV} \%)<50$ (OR $2.27(95 \%$ $\mathrm{Cl} 1.55$ to 3.21 ), $p=0.014$ ), $>4$ exacerbations in the past year (OR 6.9 (95\% $\mathrm{Cl} 0.08$ to 1.08 ), $p=0.028$ ) and previous hospitalisations due to COPD (OR 4.13 (95\% $\mathrm{Cl} 1.02$ to 16.07), $\mathrm{p}=0.041$ ) were associated with the presence of PPMs in the distal airways. The operative characteristics for predicting distal airway infection when patients presented with purulent exacerbation were as follows: sensitivity $89.5 \%$, specificity $76.2 \%$, positive predicted value $77.3 \%$ and negative predicted value $88.9 \%$.

Conclusions: The self-reporting presence of purulence in the sputum, as well as common previous exacerbations and hospitalisations due to COPD in patients with severe airflow obstruction $\left(\mathrm{FEV}_{1} \%<50\right)$ predict the presence of bacterial infection in the distal airways. The use of these clinical variables may help in selecting candidates to receive antibiotic treatment.
$\mathrm{C}$ hronic obstructive pulmonary disease (COPD) is associated with intermittent exacerbations that present with worsening symptoms and lung function impairment. These exacerbations contribute to the morbidity and mortality in patients with COPD and considerably affect the quality of life experienced by patients. ${ }^{12}$

Most exacerbations are associated with the presence of bacterial pathogens in the lower respiratory tract, although the real cause-effect of bacteria on exacerbations is unclear. Viruses and, to a lesser extent, exposure to allergens or pollutants may also precipitate a sudden deterioration. ${ }^{3}$ Although antibiotics are commonly prescribed in COPD exacerbations, evidence of efficacy is debatable, with some controlled studies showing a benefit, whereas others do not. ${ }^{5}$ The uncontrolled use of antibiotics in COPD exacerbations is enormously expensive and may contribute to the serious problem of emerging resistance to valuable antibiotics. ${ }^{6}$

Anthonisen et al, in a landmark study, ${ }^{7}$ showed that patients presenting with at least two of the three cardinal symptoms of exacerbation-increased dyspnoea, increased sputum volume and sputum purulence-experienced a clear benefit from antibiotic treatment. However, this study was based on an outpatient population, microbiological samples of respiratory secretions were not taken and the bacterial aetiology of the exacerbations was never confirmed. Bacterial pathogens can be isolated from sputum during exacerbations. Although this technique is simple and cost effective, it is often omitted in the clinical management of patients with COPD exacerbations.
Sample contamination by oropharyngeal flora and the difficulties in obtaining a good sputum sample are the main shortcomings that justify this omission. ${ }^{8}$

Quantitative culture of protected specimen brush (PSB) is considered the gold standard for the diagnosis of distal airway infections because of its potential for obtaining sterile microbial samples. ${ }^{9}{ }^{10}$ However, the invasiveness inherent to the bronchoscopic evaluation precludes its use in clinical practice. In this sense, the identification of reliable clinical predictors of bacterial infection as a cause of severe exacerbations based on PSB findings might be of critical importance, as it would help to promote a more judicious use of antibiotics in this clinical setting.

In this study on patients with severe COPD exacerbations requiring hospitalisation, we aimed to (1) identify potential, easy-to-obtain, clinical predictors of bacterial infection as a cause of exacerbation, taking PSB samples as the gold standard and (2) assess the role of sputum culture as an alternative diagnostic technique in this clinical setting.

Abbreviations: CFU, colony-forming units; COPD, chronic obstructive pulmonary disease; $\mathrm{FEV}, \%$, percentage predicted forced expiratory volume in $1 \mathrm{~s}$; FVC, forced vital capacity as a percentage of predicted; MIC, minimum inhibitory concentration; $\mathrm{PaCO}_{2}$, arterial $\mathrm{CO}_{2}$ pressure; $\mathrm{PaO}_{2}$, arterial oxygen pressure; PPM, potential pathogenic microorganism; PSB, protected specimen brush 


\section{POPULATION AND METHODS Study population}

The study was conduced from October 2002 to April 2004 in a respiratory care unit at the Hospital Clínic, Barcelona, Spain. During this period, selected patients with COPD exacerbation requiring hospitalisation were screened for participation. Patients were evaluated within the first $24 \mathrm{~h}$ after admission to the emergency department. The ethics committee of the hospital approved the study protocol and written informed consent was obtained from each patient.

\section{Definitions}

COPD was defined and categorised according to the Global Initiative for Chronic Obstructive Lung Disease guidelines. ${ }^{11}$ Airflow obstruction was defined as a post-bronchodilatador ratio of percentage predicted forced expiratory volume in $1 \mathrm{~s}$ to forced vital capacity as a percentage of predicted $\left(\mathrm{FEV}_{\mathrm{l}} / \mathrm{FVC}\right)$ of $\leqslant 0.7$. The degrees of obstruction were as follows: mild, $\mathrm{FEV}_{1} \%$ predicted $\geqslant 80 \%$; moderate, $\mathrm{FEV}_{1} \%$ predicted $50-80 \%$; severe, $\mathrm{FEV}_{1} \%$ predicted $30-50 \%$; and very severe, $\mathrm{FEV}_{1} \%$ predicted $<30 \%$. Patients with a bronchodilatador reversibility test $>200 \mathrm{ml}$ or $>12 \%$ predicted were not included.

Sputum purulence was considered when patients referred to a change in the colour of sputum over the past $72 \mathrm{~h}$ from uncoloured to yellow-green.

Admission criteria for patients with COPD exacerbation Although guidelines for the diagnosis and care of patients with COPD were considered, ${ }^{211}$ the ultimate decision on whether patients required admission from the emergency department to the respiratory ward was taken by the pneumologist in charge after careful evaluation of their particular clinical characteristics and results of their biochemistry and arterial blood gases.

All patients were reassessed clinically 4 weeks after discharge from hospital. Treatment outcome was judged successful when the patient did not have impairment in respiratory symptoms requiring additional outpatient visits, any increase in the baseline treatment or hospital readmission.

\section{Exclusion criteria}

Common exclusion criteria were as follows: (1) previous diagnosis of bronchiectasis; (2) clinical and radiological evidence of pneumonia or congestive heart failure; (3) necessity of mechanical ventilation on admission; (4) diagnosis of neoplasm or any type of immunosuppression; (5) previous hospitalisation during the past 4 weeks; and (6) any type of antibiotic treatment received over the 4 weeks before admission.

\section{Study protocol}

Demographic data, evaluation of current symptoms, number of prior exacerbations requiring hospitalisation, relevant comorbid conditions, current treatment and stay in hospital were retrieved by means of a standardised questionnaire. Biochemical results, chest $x$ ray films and arterial blood gas analysis were obtained in all patients at admission from the emergency department.

Most $(n=36)$ patients included in the investigation had undergone a pulmonary function evaluation over the past 46 months before the exacerbation. If these data were not available, forced spirometry test (Collins Survey III Plus, Braintine, Mass, USA) was conducted at least 2 months after the exacerbation when patients remained in a clinically stable condition. ${ }^{12}$

A sample of spontaneous sputum for microbiological evaluation was obtained from all patients. Patients then received nebulised bronchodilatadors (albuterol sulphate $5 \mathrm{mg}$ and ipratropium bromide $250 \mu \mathrm{g}$ ) and intravenous prednisolone.
Bronchoscopy was performed within the first $24 \mathrm{~h}$ after admission. Upper airway anaesthesia was achieved by nebulisation of $8 \mathrm{ml}$ of lidocaine $5 \%$ through a buccal clip for $15 \mathrm{~min}$. Flexible bronchoscopy (Olympus BF 30; Olympus, New Hyde Park, New York, USA) was performed transnasally, avoiding any suction through the inner channel. Using the technique described by Wimberley et al, ${ }^{13}$ a PSB sample (Microbiology Brush; Mill-Rose Laboratory, Mentor, Ohio, USA) was obtained from a segmental orifice of the middle lobe or the right lower lobe. Oxygen supplementation was given to all patients by a nasal catheter. The following criteria were considered as formal contraindications to perform the bronchoscopy: (1) changes in mental status, (2) dyspnoea at rest and (3) severe or worsening hypoxaemia and hypercapnia with respiratory acidosis.

Once bronchoscopy was performed, empirical antibiotic treatment (oral amoxicillin-clavulanate, oral levofloxacin, oral clarithromycin or intravenous ceftriaxone) was initiated and the regimen was later adjusted according to microbiological results obtained by PSB specimens. Antimicrobial treatment was not stopped in the case of negative microbiological findings.

\section{Microbiological evaluation}

Sputum samples were collected in sterile vials and processed in the laboratory within $2 \mathrm{~h}$ after collection. Gram's staining of sputum in the area of maximal purulence was examined for leucocytes and epithelial cells. Only sputum samples of Murray-Washington classification degrees IV or $\mathrm{V}$ were processed for culture (degree IV, 10-25 epithelial cells and $>25$ leucocytes per field; degree $\mathrm{V}, \leqslant 10$ epithelial cells and $>25$ leucocytes per field using a low magnification lens $(\times 100)) \cdot{ }^{14}$ Sputum specimens not fulfilling these criteria were not considered to be representative of distal airways and were not processed for culture. PSB samples were serially diluted (1:10, $1: 100$ and 1:1000). All microbiological specimens were plated on blood, chocolate, Wilkins-Chalgren and Sabouraud's agar, and Ziehl-Neelsen staining and Lowenstein culture were performed on all samples. The cultures were evaluated for growth after $48 \mathrm{~h}$, negative bacterial cultures for fungi after 4 weeks and Lowenstein cultures after 6 weeks. Susceptibility testing was performed using the broth microdilution or $\beta$-lactamase test, and samples were classified as sensitive, intermediate or resistant according to the criteria published by the National Committee for Clinical Laboratory Standards. ${ }^{15}$ The results of the PSB were expressed quantitatively as colonyforming units $(\mathrm{CFU}) / \mathrm{ml}$. Bacterial load was considered significant when it reached $\geqslant 10^{2} \mathrm{CFU} / \mathrm{ml}$ in PSB specimens, as described by Cabello et al. ${ }^{16}$

Microorganisms identified according to standard methods ${ }^{17}$ were classified as potential pathogenic microorganisms (PPMs), which included Haemophilus influenzae, Streptococcus pneumoniae, Moraxella catarrhalis, Gram-negative bacilli, Pseudomonas aeruginosa and Staphylococcus aureus, and non-potential pathogenic microorganisms (non-PPMs), which included Streptococcus viridans, Neisseria spp, Candida spp, Corynebacterium spp, H parainfluenzae and Staphylococcus epidermidis.

Paired serum samples for serology were collected (at hospital admission and within weeks 3 and 6 thereafter) for Mycoplasma pneumoniae, Chlamydia pneumoniae, Legionella pneumophila, Coxiella burnetii and respiratory viruses (influenza viruses A and B, parainfluenza viruses 1, 2 and 3, respiratory syncytial virus and adenovirus). The presence of an infection by atypical bacteria or respiratory viruses was established according to the criteria described previously. ${ }^{18}$

\section{Statistical analysis}

Continuous variables are reported as medians (range). Continuous variables were compared using the non-parametric 


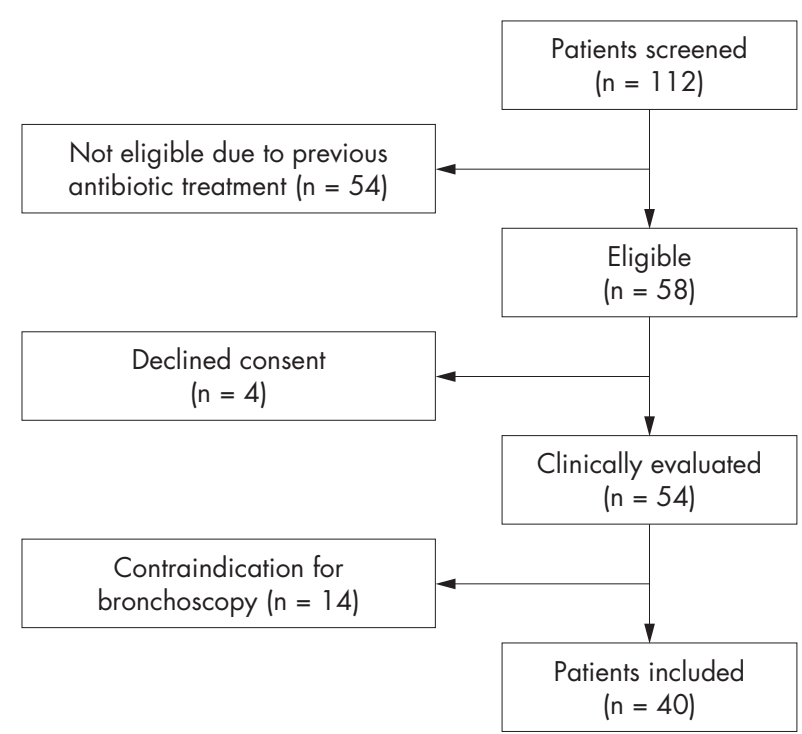

Figure 1 Study profile.

Mann-Whitney $U$ test and categorical variables by the $\chi^{2}$ test or Fisher's exact test when appropriate. All reported $p$ values were two tailed and the level of significance was 5\%; $\kappa$ coefficient was used to measure the agreement between sputum and PSB samples. Only valuable sputum samples were considered for correlations with PSB.

The potential influence of different variables on the presence of PPMs in the distal airways was evaluated by univariate analysis. The assessed variables were as follows: smoking habit (0, current smoker; 1 , past smoker), pulmonary function $(0$, $\left.\mathrm{FEV}_{1} \geqslant 50 \% ; 1, \mathrm{FEV}_{1}<50 \%\right)$, presence of comorbidities (0, no; 1 , yes), previous oral corticosteroid (daily oral prednisone $>10 \mathrm{mg}$ ) treatment $(0$, no; 1 , yes $)$, number of exacerbations in the past year $(0,<4 ; 1, \geqslant 4)$, number of hospitalisations during the past 3 years $(0,0 ; 1, \geqslant 1)$; sputum characteristics $(0$, mucous; 1 , purulent), fever at admission ( 0 , no; 1 , yes $)$, arterial oxygen pressure $\left(\mathrm{PaO}_{2}\right)$ at admission $(0, \geqslant 60 ; 1,<60 \mathrm{~mm} \mathrm{Hg})$, arterial $\mathrm{CO}_{2}$ pressure $\left(\mathrm{PaCO}_{2}\right)$ at admission $(0,<45 ; 1$, $\geqslant 45 \mathrm{~mm} \mathrm{Hg}$ ), and white cell count at admission (0, $<12 \times 10^{9} / \mathrm{l} ; 1, \geqslant 12 \times 10^{9} / \mathrm{l}$ ). Adjusted odds ratios (ORs) with $95 \%$ confidence intervals (CIs) were computed for variables associated with the presence of PPMs in the airways. All data were analysed using the statistical package SPSS for Windows V.10.0.

\section{RESULTS}

\section{Patients}

During the study period, 112 patients with COPD exacerbations admitted to the emergency room and requiring hospitalisation were screened (fig 1), of whom 54 were excluded because they had received antibiotics in the previous month, 4 patients refused to undergo bronchoscopy, and in 14 patients this technique was considered too risky because of clinical and/or arterial blood gas deterioration. The median (range) predicted $\mathrm{FEV}_{1} \%$ was 37 (19-72), predicted $\mathrm{FVC} \%$ was 75 (64-89) and $\mathrm{FEV}_{1}: \mathrm{FVC} \%$ was 42 (34-67). In all, 21 (53\%) patients were taking inhaled steroids (maximum $1600 \mu \mathrm{g} /$ day) and 9 (23\%) were receiving daily oral steroid treatment (maximum $10 \mathrm{mg}$ / day). All patients complained of increased breathlessness at presentation, $20(50 \%)$ had increased sputum volume and 22 (55\%) reported purulent sputum over the $48-72 \mathrm{~h}$ before admission (table 1).
Table 1 Characteristics of patients with severe exacerbations of chronic obstructive pulmonary disease and requiring hospitalisation $(n=40)$

\begin{tabular}{|c|c|}
\hline Characteristic & Values \\
\hline Age, years & $69(43-83)$ \\
\hline Male & $40(100)$ \\
\hline Current smoker & $6(15)$ \\
\hline Past smoker & $34(85)$ \\
\hline Comorbid conditions & $26(65)$ \\
\hline Cardiovascular disease & $21(52)$ \\
\hline Diabetes mellitus & $6(15)$ \\
\hline Renal failure & $2(5)$ \\
\hline \multicolumn{2}{|l|}{ Exacerbations in the past year } \\
\hline$<4$ episodes & $19(48)$ \\
\hline$>4$ episodes & $21(52)$ \\
\hline \multicolumn{2}{|l|}{ Exacerbation criteria } \\
\hline Increased dyspnoea & $40(100)$ \\
\hline Increased sputum volume & $10(25)$ \\
\hline Purulent sputum & $22(55)$ \\
\hline Fever at admission & $12(30)$ \\
\hline Domiciliary oxygen & $10(25)$ \\
\hline Oral steroid treatment ${ }^{*}$ & $9(22)$ \\
\hline $\mathrm{FEV}_{1} \%$ predicted & $37(19-72)$ \\
\hline FVC\% predicted & $69(64-89)$ \\
\hline $\mathrm{FEV}_{1} / \mathrm{FVC} \%$ & $42(34-67)$ \\
\hline White cell count, $\times 10^{9} / 1$ & $11590(5100-22700)$ \\
\hline $\mathrm{PaO}_{2}, \mathrm{~mm} \mathrm{Hg}$ & $62(40-75)$ \\
\hline $\mathrm{PaCO}_{2}, \mathrm{~mm} \mathrm{Hg}$ & $44(23-62)$ \\
\hline \multicolumn{2}{|c|}{$\begin{array}{l}\mathrm{FEV} \text {, forced expiratory volume in } 1 \mathrm{~s} \text { as a percentage of predicted; } \mathrm{FVC} \\
\text { forced vital capacity as a percentage of predicted; } \mathrm{PaCO}_{2} \text {, arterial } \mathrm{CO}_{2} \\
\text { pressure; } \mathrm{PaO}_{2} \text {, arterial oxygen pressure. } \\
\text { Values are median (range) or } \mathrm{n}(\%) \text { as appropriate. } \\
{ }^{*} \text { More than } 10 \mathrm{mg} \text { of prednisolone daily. }\end{array}$} \\
\hline
\end{tabular}

We found no differences between patients with purulent exacerbations $(\mathrm{n}=22)$ and those with mucoid exacerbations $(\mathrm{n}=18)$ regarding age, smoking habit, forced spirometry data, use of domiciliary oxygen, presence of comorbidities, current inhaled drugs ( $\beta$-agonists, ipratropium bromide or corticosteroids), $\mathrm{PaO}_{2}$ or $\mathrm{PaCO}_{2}$ values at admission, and days of hospitalisation.

\section{Respiratory samples}

Bronchoscopy-guided PSB samples were obtained in the 40 patients included in the study. No serious complications during the bronchoscopy procedure were evidenced.

Cultures of PSB at $\geqslant 10^{2} \mathrm{CFU} / \mathrm{ml}$ yielded 23 PPMs in 18 of 40 $(45 \%)$ patients. The concentration reached a cut-off of $\geqslant 10^{3}$ in 13 of the 18 patients with PPMs in the PSB. Also, PSB cultures showed growth of 21 non-PPMs in $10(25 \%)$ patients. The most frequent PPMs isolated were Streptococcus pneumoniae $(\mathrm{n}=7$, $17.5 \%), H$ influenzae $(\mathrm{n}=7,17.5 \%)$, Pseudomonas aeruginosa $(\mathrm{n}=4,10 \%)$ and $M$ catarrhalis $(\mathrm{n}=2,5 \%)$.

A sputum sample was obtained spontaneously from all 40 patients, but only 18 (45\%) fulfilled the Murray-Washington criteria (grade IV or V) and were further processed for culture. ${ }^{13}$ Culture of good-quality sputum samples yielded 16 PPMs corresponding to 14 (35\%) patients and 4 non-PPMs reported as mixed community flora corresponding to $4(10 \%)$ patients (table 2).

Four patients with considerable concentrations of PPMs in the PSB samples had a negative sputum culture. By contrast, only one patient with a positive sputum culture had a negative PSB specimen (fig 2). Accordingly, for the PPMs recovered above the predefined cut-off of $\geqslant 10^{2} \mathrm{CFU} / \mathrm{ml}$, the results of PSB and sputum cultures agreed in $85 \%$ of the patients $(\kappa=0.85, \mathrm{p}<0.002)$. 


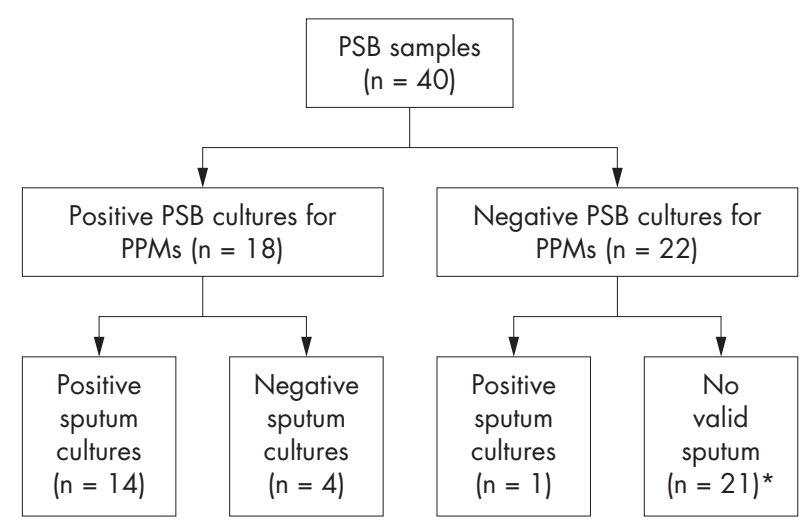

Figure 2 Microbiological profile. PPM, potentially pathogenic microorganism; PSB, protected specimen brush. *All samples contained $<25$ neutrophils/low-power field.

\section{Serology}

Serological samples were positive according to the established criteria in 7 of $39(18 \%)$ cases, with 2 cases of Chlamydia pneumoniae, 2 cases of influenza A virus, and one case each of $M$ pneumoniae, parainfluenza virus and respiratory syncytial virus. Two patients with serological evidence of Chlamydia pneumoniae infection had a concomitant $H$ influenzae isolated in the PSB samples.

Susceptibility tests to antibiotics were performed for the PPMs isolated by PSB. Of the $7 \mathrm{H}$ influenzae strains isolated, 3 (43\%) were $\beta$-lactamase positive and, of the 4 strains of $M$ catarrhalis isolated, $3(75 \%)$ were $\beta$-lactamase positive. Two strains of Streptococcus pneumoniae showed high resistance to penicillin (minimum inhibitory concentration (MIC) $\geqslant 2 \mu \mathrm{g} /$ $\mathrm{ml}$ ), two strains had intermediate resistance (MIC 0.1-1.0 $\mu \mathrm{g}$ / $\mathrm{ml}$ ) and only three strains were susceptible to penicillin (MIC $\leqslant 0.06 \mu \mathrm{g} / \mathrm{ml})$.

\section{Predictive factors associated with distal airway infection by PPMs}

The results of the univariate analysis showed that factors associated with the presence of PPMs in the distal respiratory tract were the self-reporting patient observation of sputum purulence $(\mathrm{p}<0.001)$, a severe airflow obstruction defined by a
$\mathrm{FEV}_{1} \%<50 \%(\mathrm{p}=0.014),>4$ exacerbations in the past year $(\mathrm{p}=0.028)$ and being hospitalised at least once for COPD exacerbation over the last 3 years $(p=0.041)$ (table 3$)$. Factors not related to the presence of PPMs in the lower airways were smoking habit, $\mathrm{PaO}_{2}$ and $\mathrm{PaCO}_{2}$ values at admission, previous domiciliary oxygen therapy and inhaled or oral steroid treatment. The results of the univariate analysis did not change when a cut-off of $\geqslant 10^{3} \mathrm{CFU} / \mathrm{ml}$ was considered.

\section{Clinical relevance of the sputum analysis}

Of the 22 patients, 17 (77\%) who reported a purulent appearance of the sputum had PPMs above the predefined cut-off point in the PSB sample, but only $5(23 \%)$ of them had negative cultures. By contrast, only 1 patient who reported mucoid sputum had considerable PPMs in the PSB sample (fig 3). This was the only patient with a good-quality sputum sample that was further processed for culture. Using $10^{2} \mathrm{CFU} /$ $\mathrm{ml}$ in the PSB, the operative characteristics for predicting lower airway infection when patients reported the presence of purulent sputum were as follows: sensitivity $89.5 \%$, specificity $76.2 \%$, positive predictive value $77.3 \%$ and negative predictive value $88.9 \%$. Likewise, the corresponding operative characteristics for the valid sputum cultures at admission were $72.2 \%$, $89.4,92.9 \%$ and $95.5 \%$.

When Anthonisen criteria were analysed, 20 patients presented three cardinal symptoms at admission (type 1 exacerbations), 12 presented two criteria with sputum purulence in only two cases (type 2 exacerbations) and 8 patients presented one criteria, exclusively for increased dyspnoea (type 3 exacerbations). We found that the airway infection rate by PPMs in patients with exacerbation types 1,2 or 3 was $80 \%$, $35 \%$ and $6 \%$, respectively. The effect of increased dyspnoea and increased sputum volume was negligible when analysing these two major criteria independently.

\section{DISCUSSION}

This study shows that purulence in the sputum is the hallmark of bacterial airway infection in patients with COPD exacerbation. Contrary to patients with mucoid sputum, most of those who reported purulence had positive PSB cultures with high PPM counts in distal airways. This finding emphasises the usefulness of simple cardinal symptoms in selecting candidates to receive antibiotics, even in the context of severe exacerbations requiring hospitalisation.

Table 2 Bacterial microorganisms isolated in sputum and protected specimen brush samples

\begin{tabular}{|c|c|c|c|c|}
\hline \multirow[b]{2}{*}{ Bacterial load, CFU/ml } & \multirow[t]{2}{*}{$\begin{array}{l}\text { Sputum } \\
\text { samples } \\
n=40\end{array}$} & \multicolumn{2}{|c|}{ PSB samples, $n=40$} & \multirow[b]{2}{*}{$\geqslant 10^{4}$} \\
\hline & & $\geqslant 10^{2}$ & $\geqslant 10^{3}$ & \\
\hline Positive bacterial culture, n (\%) & $18(45)$ & $27(68)$ & $24(60)$ & $9(23)$ \\
\hline PPMs, n (\%)* & $14(35)$ & $18(45)$ & $13(33)$ & $4(10)$ \\
\hline Haemophilus influenzae & 5 & 7 & 7 & 4 \\
\hline Streptococcus pneumoniae & 6 & 7 & 3 & 1 \\
\hline Moraxella catarrhalis & 2 & 2 & 2 & - \\
\hline Escherichia coli & 1 & 1 & - & - \\
\hline Enterobacter spp & - & 1 & 1 & - \\
\hline Pseudomonas aeruginosa & 2 & 4 & 3 & - \\
\hline Total & 16 & 22 & 16 & 5 \\
\hline Non-PPMs, n (\%)* & $4(10)$ & $10(25)$ & $8(20)$ & $5(13)$ \\
\hline Streptococcus viridans & - & 10 & 9 & 4 \\
\hline Staphylococcus epidermidis & - & 6 & 5 & 4 \\
\hline Candida albicans & - & 2 & 1 & - \\
\hline Neisseria spp & - & 3 & 1 & - \\
\hline Mixed community flora & 4 & - & - & - \\
\hline Total & 4 & 21 & 16 & 8 \\
\hline
\end{tabular}




\begin{tabular}{|c|c|c|c|}
\hline & $\begin{array}{l}\text { Positive PSB culture, } \\
\mathrm{n} / \text { total/ }(\%)^{*}\end{array}$ & Odds ratio $(95 \% \mathrm{Cl})$ & $\mathrm{p}$ Value \\
\hline \multicolumn{4}{|c|}{ Comorbid conditions } \\
\hline Yes & $14 / 26(54)$ & $3.41(0.84$ to 6.08$)$ & 0.08 \\
\hline \multicolumn{4}{|c|}{ Domiciliary oxygen } \\
\hline Yes & $5 / 10(50)$ & $3.50(0.75$ to 16.28$)$ & 0.15 \\
\hline No & $13 / 30(43)$ & & \\
\hline \multicolumn{4}{|c|}{$\mathrm{FEV}_{1} \%$ predicted $<50$} \\
\hline Yes & $17 / 34(50)$ & $2.27(1.55$ to 3.21$)$ & 0.01 \\
\hline No & $1 / 6(16)$ & & \\
\hline \multicolumn{4}{|c|}{ Oral steroid therapy } \\
\hline Yes & $4 / 9(44)$ & 0.85 (0.19 to 3.79$)$ & 0.83 \\
\hline No & $14 / 31(45)$ & & \\
\hline \multicolumn{4}{|c|}{ Current smoking habit } \\
\hline Yes & $3 / 6(50)$ & $0.89(0.16$ to 2.88$)$ & 0.89 \\
\hline No & $15 / 34(44)$ & & \\
\hline \multicolumn{4}{|c|}{ Fever at admission } \\
\hline Yes & $5 / 12(42)$ & $3.39(0.57$ to 10.10$)$ & 0.16 \\
\hline \multirow{2}{*}{\multicolumn{4}{|c|}{$\mathrm{PaO}_{2}$ at admission $<60 \mathrm{~mm} \mathrm{Hg}$}} \\
\hline & & & \\
\hline Yes & $11 / 20(55)$ & 2.78 (0.77 to 10.04$)$ & 0.11 \\
\hline No & $7 / 20(55)$ & & \\
\hline \multicolumn{4}{|c|}{$\mathrm{PaCO}_{2}$ at admission $>45 \mathrm{~mm} \mathrm{Hg}$} \\
\hline Yes & $7 / 19(37)$ & $0.29(0.08$ to 1.08$)$ & 0.15 \\
\hline \multirow{2}{*}{\multicolumn{4}{|c|}{ White cell count $>12 \times 10^{9} / 1$}} \\
\hline & & & \\
\hline Yes & $13 / 25(52)$ & $1.62(0.44$ to 5.94$)$ & 0.46 \\
\hline No & $5 / 15(33)$ & & \\
\hline \multicolumn{4}{|c|}{$\geqslant 4$ exacerbations in the past year } \\
\hline Yes & $13 / 21(62)$ & 6.91 (1.24 to 38.52$)$ & 0.03 \\
\hline No & $5 / 19(26)$ & & \\
\hline \multicolumn{4}{|c|}{ Hospitalisation in the past 3 years } \\
\hline Yes & $14 / 25(56)$ & $4.13(1.02$ to 16.67$)$ & 0.04 \\
\hline \multicolumn{4}{|c|}{ Purulent sputum } \\
\hline Yes & $17 / 22(78)$ & 27.20 (4.60 to 60.69$)$ & 0.001 \\
\hline No & $1 / 18(5)$ & & \\
\hline
\end{tabular}

Although culture of good-quality sputum samples reliably reproduces distal airway infection by PPMs, the high number of technical unsatisfactory samples limits its clinical use. ${ }^{19}$

Different studies using sputum cultures have shown good correlations between purulence and bacterial exacerbations, ${ }^{20-22}$ but our study is the first using uncontaminated PSB specimens as a gold standard to define the presence or absence of distal airway infection. Interestingly, our results show that a

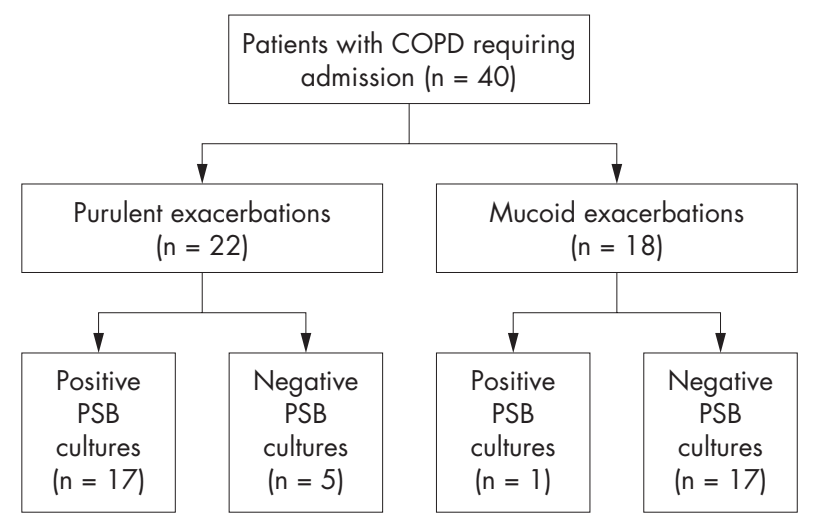

Figure 3 Relationships between sputum characteristics and protected specimen brush (PSB) results of patients with chronic obstructive pulmonary disease (COPD). self-reporting presence of purulence in the sputum predicts the presence of bacteria at high concentrations in the airways with a positive predictive value of $77 \%$ and a negative predictive value of $89 \%$. Also, being hospitalised previously, >4 COPD exacerbations per year and a severe airway obstruction $\left(\mathrm{FEV}_{1}\right.$ $<50 \%$ ) reinforce the probability of having high bacterial counts in the distal airways. Although these data seem to be reliable for deciding which patients should and which should not be treated with antibiotics, several precautions must be taken into account for the proper evaluation of these results. Firstly, we have not performed a multivariate analysis to better identify variables independently associated with the presence of high bacterial counts in the distal airways, because this method might be influenced by the small sample size of the population evaluated and the results obtained might be difficult to interpret. Secondly, our population comprised selected patients with severe COPD exacerbation who had not received antibiotics and who were fit enough to undergo a bronchoscopic exploration. Further, although PSB is considered a gold standard for defining infection in patients with pneumonia, there is a lack of technical standardisation for performing this technique in patients with COPD exacerbations. Finally, after bronchoscopy, all included patients were treated with antibiotics precluding any conclusion with regard to the outcome of the exacerbation. In this sense, our results must clearly be confirmed in properly designed clinical studies evaluating the response to antibiotics in unselected patients with and without the criteria of purulent sputum. Also, and as pointed out by 
Niederman, it is necessary to use end points other than bacteriological eradication, such as time to resolution of symptoms or disease-free intervals. ${ }^{23}{ }^{24}$ The pathogenic role of bacteria in exacerbations is controversial. It is well known that bacteria chronically colonise the airways of some patients with COPD, but the mere presence of bacteria in airway secretions does not necessarily establish their aetiological role in exacerbation. ${ }^{25}$ We used quantitative cultures of PSB samples as a gold standard to define the presence or absence of bacterial infection..$^{10}$ Recently, Rosell $e t a l^{26}$ performed a pooled analysis of different studies that used PSB in patients with COPD. ${ }^{26}$ On the basis of the results obtained in 337 individuals ( 70 healthy people, 181 patients with stable COPD and 36 patients with exacerbations), these authors established a threshold of $10^{2} \mathrm{CFU} / \mathrm{ml}$ as abnormal. The prevalence of positive cultures of $\geqslant 10^{2} \mathrm{CFU} / \mathrm{ml}$ was much higher in patients with COPD exacerbations than in those with stable COPD. Colonisation by PPMs was observed in almost $30 \%$ of patients with stable COPD, but a minimal proportion had bacteria in high concentrations. In our study, 13 of the $18(72 \%)$ patients with PPMs above the predetermined threshold had counts of $\geqslant 10^{3} \mathrm{CFU} / \mathrm{ml}$, a threshold that is normally used to define pneumonia. Also, our study is unique because the patients included had not received antibiotics over the past 4 weeks, further supporting the aetiological role of the bacteria isolated in the exacerbation. Likewise, knowing that a particular patient has had previous hospitalisations for COPD exacerbation, has had $>4$ exacerbations per year and has a severe airway obstruction $\left(\mathrm{FEV}_{1}<50 \%\right)$ may reinforce the decision to prescribe antibiotics.

Contrary to Stockley et $a l^{21}$ we did not perform an analysis of the colour of the sputum. Although we acknowledge the subjectivity inherent in self-reporting, it proved to be valuable. The sensitivity and specificity of the self-reporting presence of purulence in the sputum were $90 \%$ and $76 \%$, respectively. Apart from its simplicity, the self-reporting criteria of the sputum characteristics have the added advantage that they can be evaluated in every patient. By contrast, in the series by Stockley et $a^{21}$ and in our own series, $25 \%$ and $35 \%$ of the patients included, respectively, had sputum samples that were not processed for culture because their quality was considered unsatisfactory. On the other hand, Murphy et al ${ }^{27}$ used molecular typing to show that sputum cultures could underestimate the frequency of bacterial colonisation of the respiratory tract. This observation confirms the limitation of sputum culture as a valid technique to evaluate the role of bacteria in exacerbations.

Purulence should be expected when bacteria are causing infection as the activation of host defences includes neutrophil recruitment to the airways. On the contrary, our results confirm that mucoid sputum rarely reflects bacterial airway infection. This finding is remarkable as in our series most of the nonvaluable sputum samples for culture came from patients who reported mucous sputum, and clinicians may be afraid of not giving antibiotics to patients with an unsatisfactory sputum sample, although they have reported that it was mucoid. In this sense, our results support the findings by Stockley et al, ${ }^{21}$ showing that patients with mucoid sputum during the acute exacerbation improved without antibiotic treatment. In this study, we could only incriminate bacteria as a cause of the exacerbation in $45 \%$ of the episodes evaluated (patients with PPMs in high concentrations in the distal airways). Our results are in accordance with those of others investigations showing that only half of the episodes of exacerbation are bacterial in origin, whereas the remainder should be attributed mainly to viruses, and to a lesser extent to toxins and other environmental causes. ${ }^{28}$ The fact that in our series, $18 \%$ of the patients evaluated had positive serology in the presence of different respiratory viruses or had atypical bacteria further emphasises the role of these microorganisms in exacerbations, as Blasi et $a l^{29}$ have recently shown using molecular typing. ${ }^{29}$ The myriad of microorganisms that potentially cause an exacerbation in patients with COPD underlines the importance of properly selecting patients who are expected to benefit from antibiotic treatment.

\section{CONCLUSION}

Our results show that $45 \%$ of the patients with a COPD exacerbation requiring hospitalisation have high concentrations of PPMs in PSB samples, suggesting a bacterial aetiology. We found that the self-reported observation of purulence in the sputum is strongly associated with the presence of bacterial COPD exacerbations. In addition, previous hospitalisations, $>4$ exacerbations per year and having severe air flow obstruction can predict the presence of high bacterial counts in the distal airways. The use of these simple parameters may help in selecting candidates to receive antibiotics; however, proper outcome-based studies are needed to confirm our results.

\section{Authors' affiliations}

Néstor Soler, Carlos Agustí, Joaquim Angrill, Antoni Torres, Servei de Pneumologia, Institut Clínic del Tòrax, Hospital Clínic, IDIBAPS Facultat de Medicina, Universitat de Barcelona, Barcelona, Spain

Jorge Puig De la Bellacasa, Servei de Microbiologia, Hospital Clínic, IDIBAPS Facultat de Medicina, Universitat de Barcelona, Barcelona, Spain Funding: This study was supported by Marató TV3 104050530 and 04040210), grant FISS (PI041136 and PI030113), Red Gira (V-2003REDG063-0), Red Respira (V-2003-REDC1 1B-0) and CIBER, CB 06/06/ 0028.

Competing interets: None declared.

\section{REFERENCES}

1 Murray CJL, Lopez AD. Mortality by cause for eight regions of the word: Global Burden of Disease Study. Lancet 1997:349:1269-76.

2 Celli BR, MacNee W, and committee members. Standards for the diagnosis and treatment of patients with COPD: a summary of the ATS/ERS position paper. Eur Respir J 2004;23:932-46.

3 Sethi S. Infectious etiology of acute exacerbations of chronic bronchitis. Chest 2000;117:S380-5.

4 Patel IS, Seemungal TA, Wilks $M$, et al. Relationship between bacterial colonisation and the frequency, character, and severity of COPD exacerbation. Thorax 2002;57:759-76.

5 Saint S, Bent S, Vittinghoff $E$, et al. Antibiotics in chronic obstructive pulmonary disease exacerbations: a meta-analysis. JAMA 1995;273:957-60.

$6 \mathrm{Kim}$ S, Emerman Ch, Cydulka RK, et al. Prospective multicenter study of relapse following emergency department treatment of COPD exacerbation. Chest 2004;125:473-81.

7 Anthonisen NR, Manfreda J, Warren CPW, et al. Antibiotic therapy in exacerbations of chronic obstructive pulmonary disease. Ann Intern Med 1987; 106:196-204.

8 Lentino J-R, Lucks D-A. Non-value of sputum culture in the management of lower respiratory tract infections. J Clin Microbiol 1987;25:693-7.

9 Monsó E, Ruiz J, Rosell A, et al. Bacterial infection in chronic obstructive pulmonary disease: a study of stable and exacerbated outpatients using the protected specimen brush. Am Respir Crit Care Med 1995;152:1316-20.

10 Soler N, Torres A, Ewig S, et al. Bronchial microbial patterns in severe exacerbations of chronic pulmonary disease (COPD) requiring mechanical ventilation. Am J Respir Crit Care Med 1998;157:1498-505.

11 Pouwels R, Buist S, Calverley P, et al. Global strategy for the diagnosis, management and prevention of chronic obstructive pulmonary disease. NHLBI/ WHO Global Initiative for Chronic Obstructive Lung Disease (GOLD) Workshop Summary. Am J Respir Crit Care Med 2001;163:1256-76.

12 Miravitlles $M$, Espinosa $C$, Fernández-Laso $E$, et al. Relationship between bacterial flora in sputum and functional impairment in patients with acute exacerbations of COPD. Chest 1999;116:40-6.

13 Wimberley N, Faling L-J, Bartlett J-G. A fiberoptic bronchoscopy technique to obtain uncontaminated lower airway secretions for bacterial culture. Am Rev Respir Dis 1979;119:339.

14 Murray P-R, Washington J-A. Microscopic and bacteriologic analysis of expectorated sputum. Mayo Clin Proc 1975;50:339-44.

15 National Committee for Clinical Laboratory Standards. Performance standards for antimicrobial susceptibility testing, Vol 17. Philadelphia, PA: NCCLS, 1997; 1:M57-100. 
16 Cabello $\mathrm{H}$. Torres A, Celis R, et al. Bacterial colonization of distal airways in healthy subjects and chronic lung disease: a bronchoscopic study. Eur Respir J 1997; 10:1137-44.

17 Ballows A, Hauser WJ, Herrmann KL, et al. Manual of clinical microbiology, 5th edn. Washington, DC: American Society of Microbiology, 1991.

18 De Roux A, Marcos MA, Garcia E, et al. Viral community-acquired pneumonia in immunocompromised adults. Chest 2004;125:1343-51.

19 Monsó E, Rosell A, Bonet G, et al. Risk factors for lower airway bacterial colonization in chronic bronchitis. Eur Respir J 1999;13:338-42.

20 Monsó E, Garcia-Aymerich, Soler N, et al. Bacterial infection in exacerbated COPD with changes in sputum characteristics. Epidemiol Infect 2003;131:799-804

21 Stockley RA, O'Brien Ch, Pye A, et al. Relationship of sputum color to nature and outpatient management of acute exacerbations of COPD. Chest 2000;117:1638-45

22 Eller J, Ede A, Schaberg T, et al. Relation between bacteriologic etiology and lung function. Chest 1998;113:1542-8.
23 Niederman MS Who should receive antibiotics for exacerbations of chronic bronchitis? A plea for more outcome-based studies. Clin Infect Dis 2004;39:987-8. 24 Van der Valk P, Monninkhof E, Van der Palen J, et al. Clinical predictors of bacterial involvement in exacerbations of chronic obstructive pulmonary disease. Clin Infect Dis 2004;39:980-6.

25 Sethi S, Evans N, Grant B, et al. New strains of bacteria and exacerbations of chronic obstructive pulmonary disease. N Engl J Med 2002;347:465-71.

26 Rosell A, Monsó E, Soler N, et al. Microbiological determinants of exacerbation in chronic obstructive pulmonary disease. Arch Intern Med 2005:165:891-7.

27 Murphy TF, Braver AL, Schiffmacher AT, et al. Persistent colonization by Haemophilus influenzae in chronic obstructive pulmonary disease. Am J Respir Crit Care Med 2004; 170:266-72

28 Rohde G, Wiethege A, Borg I, et al. Respiratory viruses in exacerbations of chronic obstructive pulmonary disease requiring hospitalisation: a case-control study. Thorax 2003:58:37-42.

29 Blasi F, Damato S, Consentini R, et al. Chlamydia pneumoniae and chronic bronchitis: association with severity and bacterial clearance following treatment Thorax 2002;57:672-6.

\section{LUNG ALERT}

Soluble interleukin 6 receptor is raised in sleep-related breathing disorder

$\Delta$ Mehra R, Storfer-Isser A, Kirchner HL, et al. Soluble interleukin 6 receptor: a novel marker of moderate to severe sleep-related breathing disorder. Arch Intern Med 2006;166:1725-31.

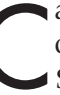
ardiovascular disease (CVD) is increased in moderate to severe sleep-related breathing disorder (SRBD). Interleukin 6 (IL6) promotes atherogenesis and elevated levels occur in SRBD. Soluble IL6 receptor (sIL6R) exerts widespread effects compared with IL6 alone. The authors examined the relationship between SRBD severity, IL6 and sIL6R levels, and morning and evening variability for each cytokine.

Subjects $(\mathrm{n}=385)$ underwent overnight polysomnography and morning and evening IL6 and sIL6R measurements. The primary exposure was moderate to severe SRBD, defined as a respiratory disturbance index $(\mathrm{RDI}) \geqslant 30$, compared with four other categories with less severe SRBD. The primary analyses were morning IL6 and sIL6R levels. Statistical models adjusted the outcomes for confounding subject characteristics such as waist circumference and comorbidities. The authors postulated that levels increase with overnight SRBD stresses and therefore adjusted for evening levels.

Adjusted morning and evening IL6 levels were not significantly higher in moderate to severe SRBD. Adjusted morning $(\mathrm{p}=0.001)$ and evening $(\mathrm{p}=0.01)$ sIL6R values were significantly higher in moderate to severe SRBD. This relationship was stronger for morning levels. Morning levels remained significantly higher even when evening levels were adjusted for $(p=0.02)$.

Limitations of the study are the potential for analytic variability of measurements and possible unmeasured confounders. The authors suggest that sIL6R may be a useful biomarker for overnight SRBD stresses and identifying patients with a higher CVD risk. A lack of specificity of an inflammatory molecule for clinical screening is a concern. Studies to assess sensitivity, positive predictive value and the effect of treating SRBD on reducing sIL6R levels and subsequent CVD risk would be of interest.

T Sathyamoorthy William Harvey Hospital, Ashford, Kent, UK; tarasathyamoorthy@yahoo.co.uk 